\title{
Eye cancer incidence in Singapore
}

Sao-Bing Lee, Kah-Guan Au Eong, Seang-Mei Saw, Tat-Keong Chan, Hin-Peng Lee

\begin{abstract}
Aim-To describe the epidemiological characteristics of patients with primary intraocular, conjunctival, and orbital cancers seen in Singapore from 1968 to 1995. Methods-Epidemiological data of all cancers diagnosed in Singapore are collected by the Singapore Cancer Registry. The data of all cases of Singapore residents with eye cancers (ICD-9, site 190) were retrieved for analysis. This includes intraocular, conjunctival, and orbital cancers but excludes cancer of the eyelids. Results-There were 125 patients of which $67(53.6 \%)$ were male and $58(46.4 \%)$ were female. The average annual age standardised incidences for male and female Singapore residents were 1.89 and 1.81 per million respectively. The most common cancer was retinoblastoma $(53.6 \%)$, followed by malignant melanoma $(19.2 \%)$ and squamous cell carcinoma (11.2\%). The most common cancer among patients younger than 15 years was retinoblastoma $(95.7 \%)$ and that for those 15 years and older was malignant melanoma $(42.6 \%)$. The most common subsite was the retina $(53.6 \%)$, followed by conjunctiva $(12.8 \%)$, orbit $(8.8 \%)$, and lacrimal gland (6.4\%).

Conclusion-The annual age standardised incidence have been stable for the 28 years studied. Retinoblastoma is much more common than melanoma in Singapore. These expanded epidemiological characteristics serve to provide ophthalmologists and epidemiologists with a foundation to monitor future disease patterns in Singapore and provide a basis for comparison with other selected populations elsewhere. (Br f Ophthalmol 2000;84:767-770)
\end{abstract}

Research Institute

S-B Lee

K-G Au Eong

T-K Chan

Department of

Community,

Occupational and

Family Medicine,

National University of

Singapore

S-M Saw

Singapore Cancer

Registry

H-P Lee

Correspondence to:

Sao-Bing Lee, Singapore Eye

Research Institute, W212,

Singapore Polytechnic, 500

Dover Road, Singapore

139651

medp8092@nus.edu.sg

Accepted for publication 3 February 2000

Cancer continues to be an important cause of death in Singapore although it has tended to level off in recent years. ${ }^{1}$ The possibility of mortality from cancer is of much concern to the local population, and vision loss from any cause is possibly the next most important health related concern. Ophthalmic malignancies are rare, accounting for about $0.15 \%$ of all cancers seen in Singapore residents from 1968 to $1992 .{ }^{1}$ As a result, detailed epidemiological descriptions of eye cancers in Singapore have not been previously reported. As this information may be of interest to ophthalmologists, epidemiologists, pathologists, healthcare administrators, and other healthcare professionals, we describe the epidemiological characteristics of 125 cases of primary intraocular, conjunctival, and orbital cancers diagnosed in Singapore from 1968 to 1995 . We have
Table 1 Charactertistics of 125 eye cancer patients (Singapore residents) in the Singapore Cancer Registry, 1968-95

\begin{tabular}{lcc}
\hline & \multicolumn{2}{c}{ Cases } \\
\cline { 2 - 3 } & No & $\%$ \\
\hline Sex & & \\
Male & 67 & 53.6 \\
Female & 58 & 46.4 \\
Race & & \\
Chinese & 97 & 13.6 \\
Malay & 17 & 5.6 \\
Indian & 7 & 3.2 \\
Others & 4 & 100 \\
Total & 125 & \\
\hline
\end{tabular}

previously described the epidemiology of eyelid malignancies in Singapore residents from 1968 to 1995 in a separate report. ${ }^{2}$

Materials and methods

We used, with permission, the data of all eye cancer cases in Singapore from 1968 to 1995 in the Singapore Cancer Registry. The Singapore Cancer Registry has collected data on cancers in Singapore since 1968. Physicians fill out a standardised form whenever a cancer is diagnosed clinically or on histopathology. Reports from all pathology laboratories and death certificates are also scrutinised and physicians are requested to provide information on cases that were not reported to the registry previously or when the forms are incomplete.

The Singapore Cancer Registry data cover all eye cancers diagnosed in Singapore, both Singapore residents and non-residents. Cases recorded by the Singapore Cancer Registry are filed according to the national registration identity card (NRIC) number. As this is a unique number for each resident in Singapore, the possibility of duplicate recording is eliminated. These cases of cancer are sourced from all death records (on computer tape), from all

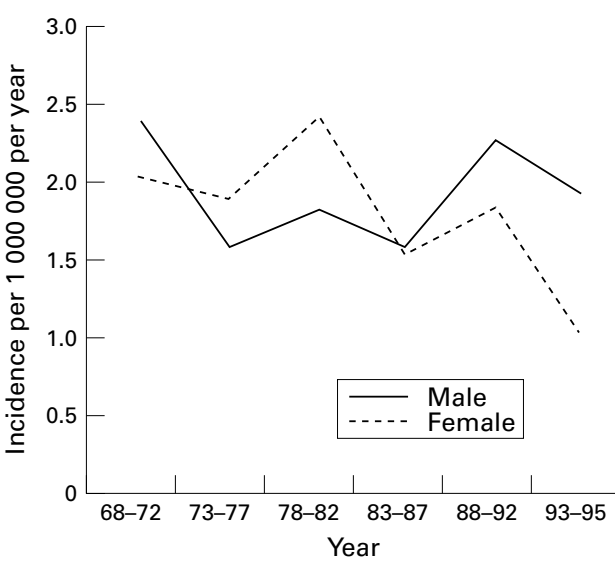

Figure 1 Age standardised (standardised to UICC world population) eye cancer incidence among Singapore residents from 1968 to 1995 . 


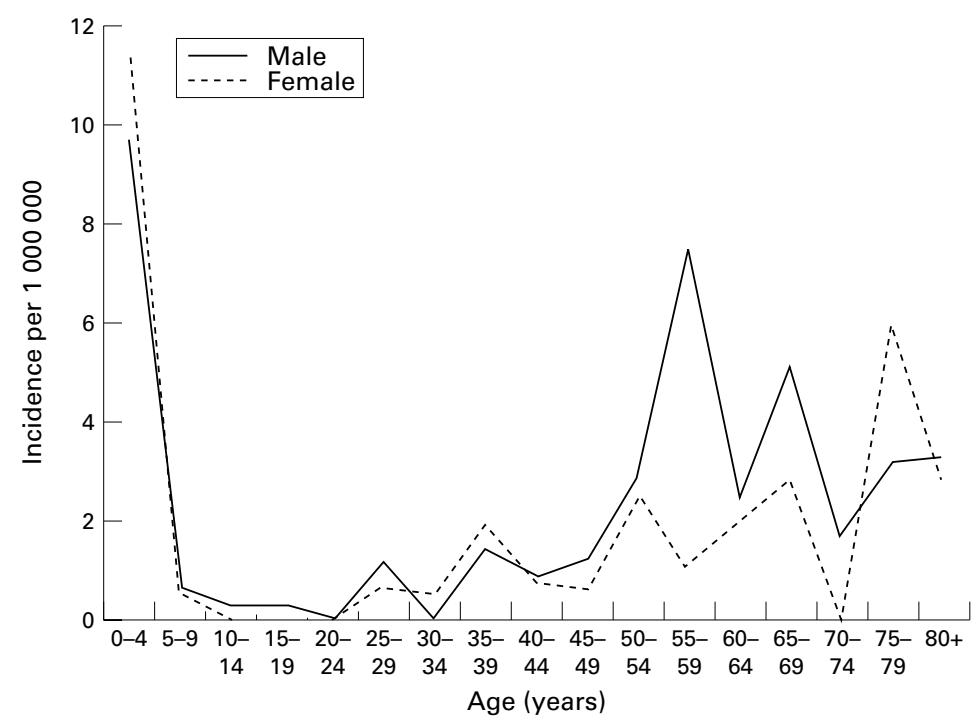

Figure 2 Average annual age specific eye cancer incidence among Singapore residents from 1968 to 1995.
Chinese and $17(13.6 \%)$ were Malay. There was a bimodal age distribution with a peak in early childhood and another at about 50 years old. In the group less than 15 years old, the median age at diagnosis was 2 years for both sexes. In the group 15 years and above, the median ages were 54 and 50 years respectively for men and women. The majority of the histological diagnoses were retinoblastoma (53.6\%), melanoma (19.2\%), and squamous cell carcinoma (SCC) $(11.2 \%)$. The most common histology seen in those younger than 15 years of age was retinoblastoma $(95.7 \%$ of those $<15$ years of age). In those 15 years of age or older, the most common histology was melanoma ( $42.6 \%$ of those $\geqslant 15$ years of age).

The average age standardised annual incidence rate for males over the 28 year period was 1.89 per million ( $95 \%$ confidence interval 1.03, 3.07 per million), and for females, 1.81 per million (95\% confidence interval 0.96, 3.1 per million). Figure 1 shows the trends for age standardised eye cancer incidence among Singapore residents from 1968 to 1995 . The rates appear stable for male residents over this 28 year period but there appears to be a decline in the rates for females with time. The average annual incidence rate is plotted for each of the 5 year period, except for the last period, which is the average of 3 years. Figure 2 presents the average annual age specific eye cancer incidence by sex among Singapore residents from 1968 to 1995 . There is a clear incidence peak in early childhood for both sexes and a distinct peak in men between 55-59 years of age.

The predominant cancer in those less than 15 years of age is retinoblastoma (95.7\%) (Table 2). In contrast, the majority of the cancers in those 15 years of age or older are melanoma $(42.6 \%)$, squamous cell carcinoma $(25.9 \%)$, and lymphoma (16.7\%) (Table 3). Since age was not clearly recorded in two cases, the total number of cases in Tables 2 and 3 is 123 instead of 125.

Table 4 presents the frequency of the various subsites of site 190 - for example, eyeball, conjunctiva, and cornea. These subsites were not clearly documented by some physicians reporting to the Singapore Cancer Registry, hence a small proportion of cases were recorded as "part unspecified" (12\%). Retina was the subsite with the highest number of cases primarily because retinoblastoma was the commonest tumour recorded. The various histologies represented in each subsite are shown in Table 5.

Table 4 Subsites of 125 eye cancers cases in Singapore residents 1968-95

Table 3 Histology of eye cancers in cases $>15$ years of age in Singapore, 1968-95

\begin{tabular}{lrc}
\hline Histology & No & $\%$ \\
\hline Melanoma & 23 & 42.6 \\
Squamous cell carcinoma & 14 & 25.9 \\
Lymphoma & 9 & 16.7 \\
Adenoid cystic carcinoma & 2 & 3.7 \\
Carcinoma, NOS & 1 & 1.85 \\
Adenocarcinoma & 1 & 1.85 \\
Liposarcoma & 1 & 1.85 \\
Retinoblastoma & 0 & 0 \\
Other histology & 3 & 5.55 \\
Total cases & 54 & 100 \\
\hline
\end{tabular}

\begin{tabular}{lrc}
\hline Subsite & No & $\%$ \\
\hline Retina (190.5) & 67 & 53.6 \\
Conjunctiva (190.3) & 16 & 12.8 \\
Orbit` (190.1) & 11 & 8.8 \\
Lacrimal gland (190.2) & 8 & 6.4 \\
Eyeball† (190.0) & 6 & 4.8 \\
Lacrimal duct (190.7) & 1 & 0.8 \\
Cornea (190.4) & 1 & 0.8 \\
Part unspecified (190.9) & 15 & 12.0 \\
Total & 125 & 100 \\
\hline
\end{tabular}

${ }^{\star}$ Connective tissue of orbit, extraocular muscles, retrobulbar tissue; excludes orbital bone.

†Except conjunctiva, cornea, retina, and choroid. 
Table 5 Histology by subsites of 125 eye cancer cases in Singapore residents, 1968-95

\begin{tabular}{|c|c|c|}
\hline & No & $\%$ \\
\hline \multicolumn{3}{|l|}{ Retina } \\
\hline Retinoblastoma & 67 & 100 \\
\hline Total & 67 & 100 \\
\hline \multicolumn{3}{|l|}{ Conjunctiva } \\
\hline Squamous cell carcinoma & 8 & 50 \\
\hline Malignant melanoma & 5 & 31.25 \\
\hline Carcinoma & 1 & 6.25 \\
\hline Lymphoma & 1 & 6.25 \\
\hline Others & 1 & 6.25 \\
\hline Total & 16 & 100 \\
\hline \multicolumn{3}{|l|}{ Orbit } \\
\hline Lymphoma & 6 & 54.55 \\
\hline Rhabdomyosarcoma & 2 & 18.18 \\
\hline Malignant melanoma & 1 & 9.09 \\
\hline Liposarcoma & 1 & 9.09 \\
\hline Haemangiopericytoma & 1 & 9.09 \\
\hline Total & 11 & 100 \\
\hline \multicolumn{3}{|l|}{ Lacrimal gland } \\
\hline Adenoid cystic carcinoma & 2 & 25 \\
\hline SCC & 2 & 25 \\
\hline Lymphoma & 2 & 25 \\
\hline Adenocarcinoma & 1 & 12.5 \\
\hline Others & 1 & 12.5 \\
\hline Total & 8 & 100 \\
\hline \multicolumn{3}{|l|}{ Eyeball } \\
\hline Malignant melanoma & 6 & 100 \\
\hline Total & 6 & 100 \\
\hline \multicolumn{3}{|l|}{ Lacrimal duct } \\
\hline Malignant melanoma & 1 & 100 \\
\hline Total & 1 & 100 \\
\hline \multicolumn{3}{|l|}{ Cornea } \\
\hline Squamous cell carcinoma & 1 & 100 \\
\hline Total & 1 & 100 \\
\hline
\end{tabular}

\section{Discussion}

The data presented have a relatively high rate of histologically verified cases-125 out of 138 cases $(90.6 \%)$. This compares favourably with other cancer registries-Birmingham, United Kingdom (92\%); Victoria, Australia (83\%); and Hong Kong $(61 \%)$ for the same site with ICD code 190 between the years $1983-7 .{ }^{4}$ The higher the proportion of histological verification of diagnosis, the more confident one can be that the neoplasm existed and, hence, the more accurate the set of data.

The cases described cover patients seen in all hospitals and clinics in Singapore. As described above, cases recorded by the Singapore Cancer Registry are filed according to the national registration identity card (NRIC) number. This eliminates the possibility of duplication as this is a unique number for each resident in Singapore. The registry runs through all death records (on computer tape), all hospital discharge summaries, and all pathology reports to source for cases of cancer. This system ensures all cases of cancer diagnosed in Singapore are recorded.

The average annual incidence rate was 1.89 per million for male residents and 1.81 per million for female residents. This is similar to reported rates in Shanghai (three per million males and two per million females) and in Japan (two per million males and three per million females) ${ }^{4}$ between 1983 and 1987 . These rates in Asia are generally lower than those described in the West. For example, the rates for New York State residents were 5.4 per million in males and 4.9 per million in females between 1975 and $1986^{7}$ and in Canada were 8.1 per million and 6.0 per million for males and females respectively between 1970 and $1982 .^{8}$

Time trends for age standardised eye cancer incidence have remained stable for male residents from 1968 to 1995 , a 28 year period (Fig 1). Although there appears to be a decline in the rates for females over this same time, this is not significant. There is a clear peak incidence in average annual age specific rates in those less than 15 years of age in both sexes (Fig 2). The median age of diagnosis in this age group is 2 years for both male and female residents. This distinct peak is contributed by the high incidence of retinoblastoma $(95.7 \%)$ in this age group and is similar to that seen in other reports. ${ }^{79}{ }^{10}$ Apart from this peak early in life, there is another other peak later in life seen in both males and females. The trends in annual age specific rates for those above 15 years of age differ from that reported for New York State residents where there was an increase in rates with increasing age from the age of 20. The median age at diagnosis of male Singapore residents 15 years or older is 54 years and in females, 50 years. This compares with 64 years and 66 years among male and female New York State residents respectively.

The most common primary malignancy was retinoblastoma (53.6\%), followed by melanoma (19.2\%) and SCC (11.2\%). This differs from that reported in the New York study $-70.4 \%$ of melanoma, $9.8 \%$ of retinoblastoma, and $9.2 \%$ of SCC. Swanson and Cloud also reported that the most common primary eye cancers seen at the University of Alabama between 1958 and 1988 was melanoma ( $59 \%)$, followed by retinoblastoma $(14 \%) \cdot{ }^{11}$ In Nigeria, $55 \%$ of eye tumours seen between 1980 and 1990 were retinoblastomas. ${ }^{12}$ In Madras, retinoblastoma was also seen most often, accounting for 32\% of cases. This was followed by SCC $(25 \%) .{ }^{13} \mathrm{It}$ can be seen that the relative frequencies of these histological types vary widely in different countries. It has been observed that most eye cancers are either melanoma or retinoblastoma in predominantly white populations. ${ }^{10}$ Among whites, light pigmentation is a risk factor for uveal melanoma ${ }^{14}$; conversely, the disease is rare among blacks. ${ }^{15}$ This suggests that ocular melanomas are also related to sun exposure just as cutaneous melanomas are and, hence, are seen in greater numbers in populations with less ocular pigmentation. This relation between uveal melanomas and sun exposure had been proposed by various researchers. ${ }^{16-19}$ Singapore has a population consisting of a majority of Chinese, Malays, and Indians (three races with more skin pigmentation than whites in general), and its incidence for melanomas is correspondingly lower than that reported in the West.

Retinoblastoma is classically a disease of infancy and young children. In this study, $95.5 \%$ of the patients with retinoblastoma were younger than 5 years old. This is comparable with an American study in which 95\% were diagnosed before the age of 5 years. ${ }^{20}$ In a study 
done in Indonesia, however, only $76.1 \%$ of the patients were less than 5 years of age, which probably reflects later diagnosis. ${ }^{21}$ The mean age at diagnosis in this study was 23 months. This is lower in comparison with 41 months reported in one study in India. ${ }^{22}$ The average annual incidence of 2.4 cases per million children for children 0-9 years. ${ }^{23}$ This incidence is lower than the annual incidence of 5.8 cases per million for children younger than 10 years from the SEER (Surveillance, Epidemiology, and End Results) database from 1974 to 1985. ${ }^{24}$ The incidence per million for children below 5 years was 4.8 per million is lower than the incidence of 10.62 per million for boys and 11.43 per million for girls below 5 years from the Third National Cancer Survey from 1969 to 1971 in the United States (less than 5 years) and the SEER data from 1974 to 1976 with 11.05 cases per million for children less than 5 years. $^{25}$

Ocular melanomas are commonly found in the choroid. ${ }^{26}$ However, no cases were listed under the subsite "choroid" in the data that we have. This is thought to be due to imprecise reporting on the part of physicians who may have reported these choroidal melanomas under the subsite of "eyeball". This illustrates the need for better documentation by physicians to facilitate future epidemiological studies. The most common site for SCC is in the conjunctiva (Table 5). This is similar to that reported in other studies. ${ }^{913} 27$

This is the first evaluation of the epidemiology of intraocular, conjunctival, and orbital cancers in Singapore. To the best of our knowledge, there are no published epidemiological studies of eye malignancies in South East Asia in the English literature. In this study, it was found that the annual incidence of eye cancers in Singapore is similar to other Asian cities but is lower than that in the West. The time trends in incidence have remained stable over the 28 year study period, with only minimum changes seen.

1 Chia KS, Lee HP, Seow A, et al. Trends in cancer incidence in Singapore 1968-1992. Singapore: Singapore Cancer Registry, Report No 4, 1996. 2 Lee SB, Saw SM, Au Eong KG, et al. Incidence of eyelid
cancers in Singapore from 1968 to 1995. Br ₹ Ophthalmol cancers in Singapo

3 World Health Organisation. Manual of the international statistical classification of diseases, injuries and causes of deaths. Vol 1. Geneva: WHO, 1977.

4 Parkin DM, Muir CS, Whelan SL, et al, eds. Cancer incidence in five continents. Vol VI. Lyons: IARC Scientific Publications No 120, 1992

5 Khoo CK. Yearbook of statistics, Singapore, 1985/86. Singapore: Singapore National Printers, 1986.

6 Cheung P. Yearbook of statistics, Singapore, 1995. Singapore: Integrated Press, 1995

7 Mahoney MC, Burnett WS, Majerovics A, et al. The epideMahoney MC, Burnett WS, Majerovics A, et al. The epide-
miology of ophthalmic malignancies in New York State. miology of ophthalmic maligna
Ophthalmology 1990;97:1143-7.

8 Ayiomamitis A. Epidemiologic features of cancer of eye, orbit and related adnexa in Canada. Can $\mathcal{F}$ Ophthalmol 1989;24:269-74.

9 Marshall EC. Epidemiology of tumors affecting the visual system. Optom Clin 1993;3:1-16.

10 Smith AB, Egan EA. The role of epidemiological investigations in the study of ocular tumors. Int Ophthalmol Chin 1980;20:63-9.

11 Swanson MW, Cloud G. A retrospective analysis of primary eye cancer at the University of Alabama at Birmingham 1958-1988. Part 1:
Assoc 1991;62:815-9.

12 Ajaiyeoba IA, Pindiga HU, Akang EE. Tumours of the eye and orbit in Ibadan. East Afr Med $\mathcal{F} 1992 ; 69: 487-9$.

13 Sunderraj P. Malignant tumours of the eye and adnexa. Indian f Ophthalmol 1991;39:6-8.

14 Gallagher RP, Elwood JM, Rootman J, et al. Risk factors for ocular melanoma: Western Canada Melanoma Study. $\mathcal{F}$ Natl Cancer Inst 1985;74:775-8.

15 Scotto J, Fraumeni JF Jr, Lee JAH. Melanomas of the eye and other non-cutaneous sites. F Natl Cancer Inst 1976;56: 489-91.

16 Egan KM, Seddon JM, Glynn RJ, et al. Epidemiology aspects of uveal melanoma. Surv Ophthalmol 1988;32:23951 .

17 Tucker MA, Shields JA, Hartge P, et al. Sunlight exposure as risk factor for intraocular malignant melanoma. $N$ Engl $\mathcal{F}$ Med 1985;313:789-92.

18 Seddon JM, Gragoudas ES, Glynn RJ, et al. Host factors, UV radiation, and risk of uveal melanoma. Arch Ophthalmol 1990;108:1274-80.

19 Holly EA, Aston DA, Char DH, et al. Uveal melanoma in relation to ultraviolet light exposure and host factors. Cancer Res 1990;50:5773-7.

20 Tamboli A, Podger MJ, Horm JW. The incidence of retinoblastoma in the United States: 1974 through 1985. Arch Ophthalmol 1990;108:128-32.

21 Nasution R, Sutjipto A. Childhood retinoblastoma. Pediatr Indones 1991;31:17-22.

22 Schultz KR, Ranade S, Neglia JP, et al. An increased relative frequency of retinoblastoma at a rural regional referral hosfrequency of retinoblastoma at a rural regional referral hos-
pital in Miraj, Maharashtram, India. Cancer 1993;72:2826 .

23 Saw SM, Tan N, Lee SB, et al. Incidence and survival characteristics of retinoblastoma in Singapore: 1968 through 1995. F Pediatric Ophthalmol Strabismus (in press).

24 Tamboli A, Podgor MJ, Horm JW. The incidence of retinoblastoma in the United States:1974 through 1985 [see? Arch Ophthalmol 1990;108:128-32.

25 Pendergrass TW, Davis S. Incidence of retinoblastoma in the United States. Arch Ophthalmol 1980;98:1204-10.

26 Grin-Jorgensen C, Berke A, Grin M. Ocular melanoma. Dermatol Clin 1992;10:663-8.

27 Malik MO, El-Sheikh EH. Tumors of the eye and adnexa in Sudan. Cancer 1979;44:293-303. 